\title{
Differences in embryonic pattern formation between Caenorhabditis elegans and its close parthenogenetic relative Diploscapter coronatus
}

\author{
VERA LAHL, JENS SCHULZE and EINHARD SCHIERENBERG* \\ Zoological Institute, University of Cologne, Germany
}

\begin{abstract}
In order to evaluate the evolutionary preservation of developmental programs during nematode embryogenesis, we searched for close relatives of the model system Caenorhabditis elegans with deviant patterns. The parthenogenetically reproducing species Diploscapter coronatus shows prominent differences to $C$. elegans. While in the 2-cell stage of $C$. elegans a rotation of the nuclear/centrosome complex is found only in the posterior $P_{1}$ cell, in $D$. coronatus cell isolation indicates that rotation takes place in a cell-autonomous manner in both blastomeres, resulting in a linear 4-cell array. In C. elegans, the $A B p$ cell becomes different from its $A B a$ sister via a germlineinduced induction. In $D$. coronatus, $A B$ daughters do not touch the germline but nevertheless execute different fates, suggesting a cell-autonomous mechanism or signaling over distance. Laser ablation experiments revealed that active migration of the EMS cell is required to transform the linearly ordered blastomeres into a 3-dimensional embryo, and the difference can be most easily explained with a heterochronic shift with respect to cell mobility. In $D$. coronatus, reversal of cleavage polarity in the germline, typical for $C$. elegans, is absent. This results in four different transient variants of posterior blastomeres which eventually merge into a single pattern prior to the onset of gastrulation. This merging includes primordial germ cell migrations of variable extent toward the gut precursor cell and suggests a specific cell-cell recognition mechanism. Cell distribution in advanced embryos is essentially indistinguishable between both species.
\end{abstract}

KEY WORDS: nematode, polarity, cell specification, pattern formation, evolution

\section{Introduction}

In the animal kingdom different early embryonic cell division patterns are found that lead to characteristic early arrangements of blastomeres, e.g., radial, spiralian or bilateral symmetric cleavage. The typical cleavage pattern in nematodes does not fit any of the above schemes. It includes a series of early asymmetric cleavages sequentially separating a small number of somatic lineage founder cells from the germline. This process had been originally identified in Ascaris (Boveri, 1899; clade 8, Fig. 1) and has been studied in much detail in Caenorhabditis elegans (clade 9 ). In the 2-cell stage the first somatic founder cell AB divides with a transverse orientation of the cleavage spindle, generating two daughters of equal developmental potential (Priess and Thomson, 1987). In contrast, its sister, the germline cell $P_{1}$ undergoes a rotation of the nuclear/centrosome complex (Hyman and White, 1987; Hyman, 1989) leading to a longitudinal orientation of the spindle and subsequently to the generation of the somatic cell EMS and a new germline cell $P_{2}$. In the resulting rhombic 4-cell embryo essential cell-cell interactions take place, in which $\mathrm{P}_{2}$ induces both of its neighbors via the Delta/Notch (ABp) and the Wnt/Frizzled (EMS) pathways, respectively. In this way $A B p$ becomes different from $A B a$, in losing its ability to react to certain later signals, and EMS is polarized such that it will divide into a muscle/pharynx percursor MS and the gut founder cell E (Mello et al., 1994; Rocheleau et al., 1997; Thorpe et al., 1997; for reviews, see Eisenmann, 2005; Greenwald, 2005). Signal transduction generally requires physical contact between signaling cells (Goldstein, 1993).

Comparative studies have shown that not all nematodes follow

Abbreviations used in this paper: $\mathrm{CAB}$, centrosome-attracting body; CCR, clear cotical regions; RFM, region of first midbody.

\footnotetext{
*Address correspondence to: Dr. Einhard Schierenberg. Zoologisches Institut, Universität Köln, Kerpener Str. 15, 50923 Köln, Germany.

Fax: +49-(0)-221-470-4987. e-mail: e.schierenberg@uni-koeln.de
} 


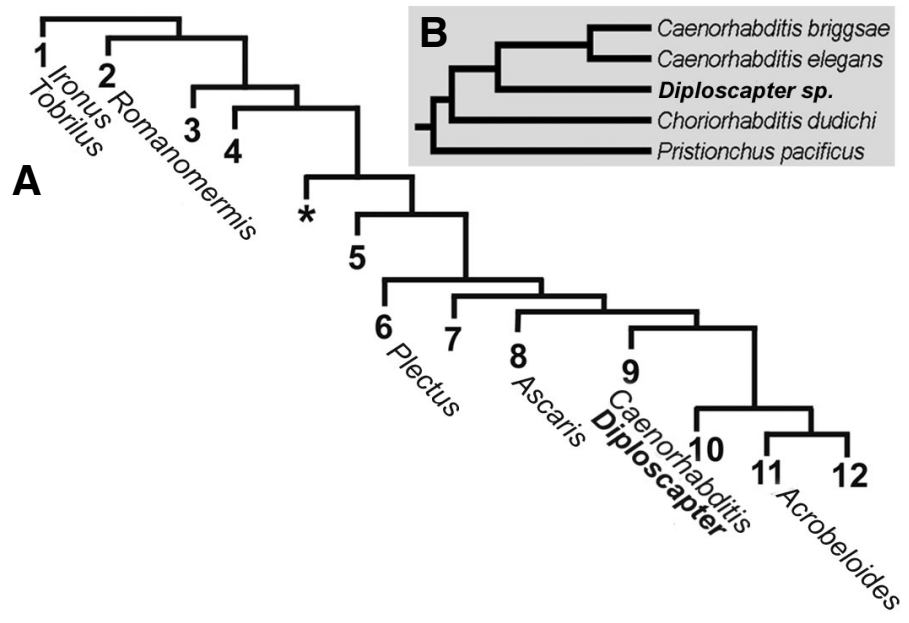

Fig. 1. Phylogenetic relationships among nematodes based on SSU rDNA sequences. (A) Phylogenetic tree with twelve clades (1-12) and one unresolved branch $\left({ }^{*}\right)$, after Holterman et al. (2006). Branch lengths reflect substitution rates and affiliations of selected representatives are shown. (B) Detail of phylogenetic tree (modified after Kiontke et al., 2007) indicating close relationship between Caenorhabditis and Diploscapter.

the $C$. elegans scheme, i.e., variants exist during the initial phase of development (Skiba and Schierenberg, 1992; Malakhov, 1994; Dolinski et al., 2001; Schierenberg, 2001; Schierenberg, 2005; Schulze and Schierenberg, 2008). A classic example is chromatin diminution in Ascaris accompanying the above-mentioned somagermline separation (Boveri, 1899). In parthenogenetic species variations in meiosis and the establishment of embryonic axes have been described (Goldstein et al., 1998; Lahl et al., 2006). Another cellular event that is found in many but not in all nematodes is a reversal of cleavage polarity in $\mathrm{P}_{2}$ (zur Strassen, 1959; Schierenberg, 1987; Skiba and Schierenberg, 1992; Laugsch and Schierenberg, 2004) which ensures that gut primordium and germline stay in physical contact. Such an association is found in many organisms and seems to be essential for normal development (Wylie, 1999). Experimental analysis revealed that in another nematode, Acrobeloides nanus (clade 11; Fig. 1), in contrast to $C$. elegans early blastomeres are multipotent and can replace lost cells (Wiegner and Schierenberg, 1998; 1999). In two members of clade 10, cell lineages and arrangements during gut formation were found to differ from $C$. elegans (Houthoofd et al., 2006).

Instead of a diamond-shaped blastomere arrangement in the 4-celled embryo, some nematode species show a linear grouping along the anterior-posterior axis (Malakhov, 1994; Dolinski et al., 2001). Such an arrangement is also found in a few close relatives of C. elegans, e.g., Diploscapter coronatus (clade 9; Tahseen et al., 1991). This unusual pattern prompted us to study early development of this species in more detail. Firstly, we wanted to know how this arrangement of cells is achieved and whether it eventually merges into a $C$. elegans-like pattern as was found earlier for other variants of nematode embryogenesis (Skiba and Schierenberg, 1992; Lahl et al., 2006). Secondly, we explored whether this pattern is compatible with the early inductions as found in $C$. elegans (see above) or whether alternative mechanisms have to be postulated to allow proper cell specification in this species.

Based mainly on molecular sequence data, a modern nematode phylogeny was suggested by Blaxter et al. (1998), extended and modified by De Ley and Blaxter (2002). Recently, from a larger set of species 339 nearly full-length small-subunit rDNA sequences were analyzed and revealed a backbone of twelve consecutive dichotomies that subdivide the phylum Nematoda into twelve clades (Holterman et al., 2006; Fig. 1). The clade numbers we use below refer to this work. A detailed modern phylogeny of rhabditid nematodes (including Diploscapter) can be found in Kiontke et al. (2007).

\section{Results}

\section{Diploscapter coronatus, a close relative of C. elegans shows a variant early development}

Looking for nematodes with early embryogenesis that differs significantly from $C$. elegans, a close relative, Diploscapter coronatus (Fig. 1), constitutes an interesting case, an initial analysis of which will be presented here. To start with, some basic features of this species are given.

Adults of $D$. coronatus are less than half the size of $C$. elegans (Fig. 2) while eggs are only about $25 \%$ shorter (average size: 42 $\mathrm{x} 20 \mu \mathrm{m} ; \mathrm{n}=52$ ), however, to a variable degree more elongated (37-48 $\mu \mathrm{m} \times 17-25 \mu \mathrm{m})$. In contrast to $C$. elegans this species reproduces parthenogenetically. Despite the absence of sperm an early axis polarity is established, but this seems to be independent of an external signal and determined randomly by chance (Lahl et al., 2006). At $20^{\circ} \mathrm{C}$ embryogenesis in D. coronatus takes 4-5 times longer than in C. elegans (Fig. 3). However, it can tolerate about $6^{\circ} \mathrm{C}$ higher temperature (i.e., $32^{\circ} \mathrm{C}$ ) and under these conditions develops only $2-3 x$ slower.

Our 4-D lineage analysis $(n=22)$ revealed that early development of $D$. coronatus is reproducible and similar enough to $C$. elegans to assign cells to specific lineages and name them according to the same standard nomenclature (Sulston et al., 1983). The sequence of early cleavages is essentially invariant, independent of temperature, but differs reproducibly from $C$. elegans. Particularly obvious are premature germline divisions, the absence of polarity reversal in the germline (see below), aspects also found in other slow developing nematodes (Skiba and Schierenberg, 1992), and a delayed cleavage of the gut founder cell E (Fig. 3).

Characteristic for the $C$. elegans 2-cell stage is the initially transverse orientation of centrosome pairs and the subsequent rotation of the nucleus/centrosome complex in the germline cell $P_{1}$ finally resulting in a rhombic 4-cell stage (see Introduction). However, this process is difficult to observe with Nomarski optics because of the inconspicious centrosomes, rapid progression

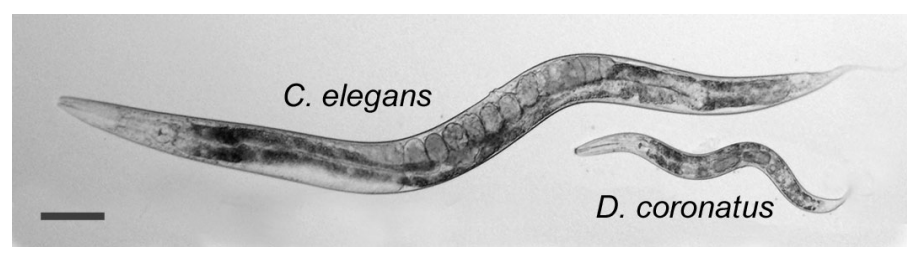

Fig. 2. Adults with eggs of Caenorhabditis elegans (top) and Diploscapter coronatus (bottom). Scale bar, $100 \mu \mathrm{m}$. 

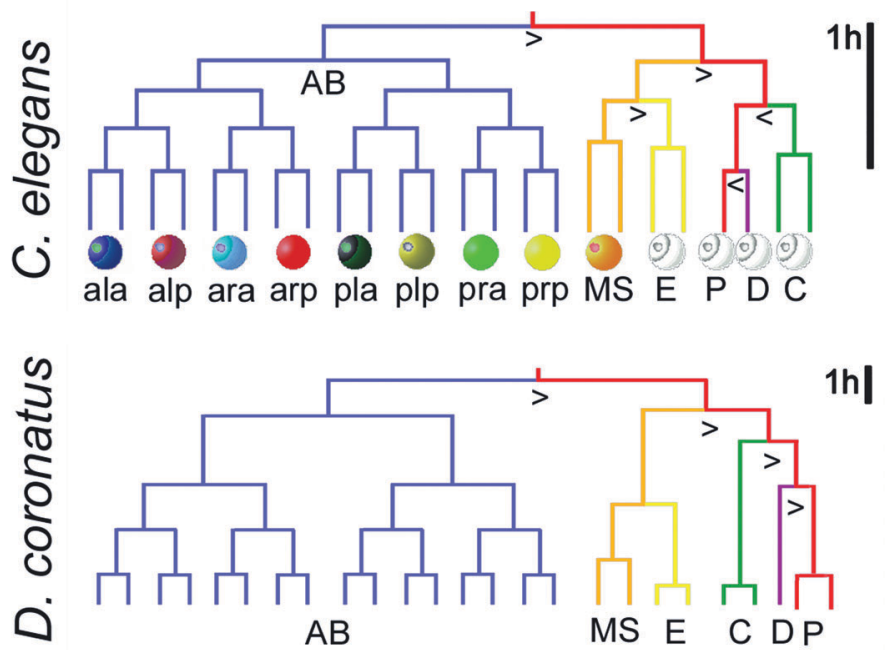

Fig. 3. Early cell lineages of $\boldsymbol{C}$. elegans and $\boldsymbol{D}$. coronatus. Arrowheads indicate unequal divisions, with tip pointing toward the smaller sister cell. Note polarity reversal in the germline (red lineage branches; for definition, see text) of C. elegans which is absent in D. coronatus. Spheres indicate color coding of cells originating from a specific lineage branch.

and cell deformation. In another so far unnamed Rhabditis species in our collection (Rhabditis sp., ES104) where the first two blastomeres divide simultaneously, this rotation is very obvious (Fig.4 B-D) as the cleavage spindle is fully developed at that time. While here positioning of centrosomes follows initially the «centriolic principle", according to which they form the mitotic spindle perpendicular to the orientation in the previous division (Costello, 1961), this principle is breached in $P_{1}$.

In contrast to this pattern, in $D$. coronatus the first four blastomeres are ususally ordered in a linear sequence (Fig. 4d). Because of variable egg shape frequently even 5 cells (Fig. 4f) or only 3 cells form a single row before blastomere rearrangement starts (see below). Further analysis made clear that this linear order corresponds to the anterior-posterior (a-p) axis of the embryo.

We wanted to know how this pattern is achieved and what consequences this has for axis formation, cell patterning and cell specification, which in $C$. elegans requires a rhombic 4-cell embryo for proper cell-cell interactions to occur (for references, see introduction).

\section{A cell-autonomous rotation of the nucleus/centrosome com- plex takes place in $P_{1}$ and $A B$}

Different from C. elegans and Rhabditis sp. (Fig. $4 \mathrm{~A}-\mathrm{F}$ ), in $D$. coronatus a rotation of the nucleus/centrosome complex takes place not only in $\mathrm{P}_{1}$ but also in $A B$, leading to the same longitudinal spindle orientation in both blastomeres (Fig. 4 a-d).

In conjunction with the rotation of the nuclear/centrosome complex in $P_{1}$, Hyman (1989) reported the formation of a small clear cortical region («cortical invagination») in the anterior cortex of the germline cell, in the area where microtubules compete for an attachment site. If such a structure is a prerequisite or a side effect of centrosome rotation, we should expect to find it in both blastomeres of the $D$.coronatus 2-cell embryo. This is in fact what we observed. Clear cortical regions (CCR) form adjacent to the anterior plasma membrane in $\mathrm{P}_{1}$ and the posterior membrane in
Rhabditis sp.
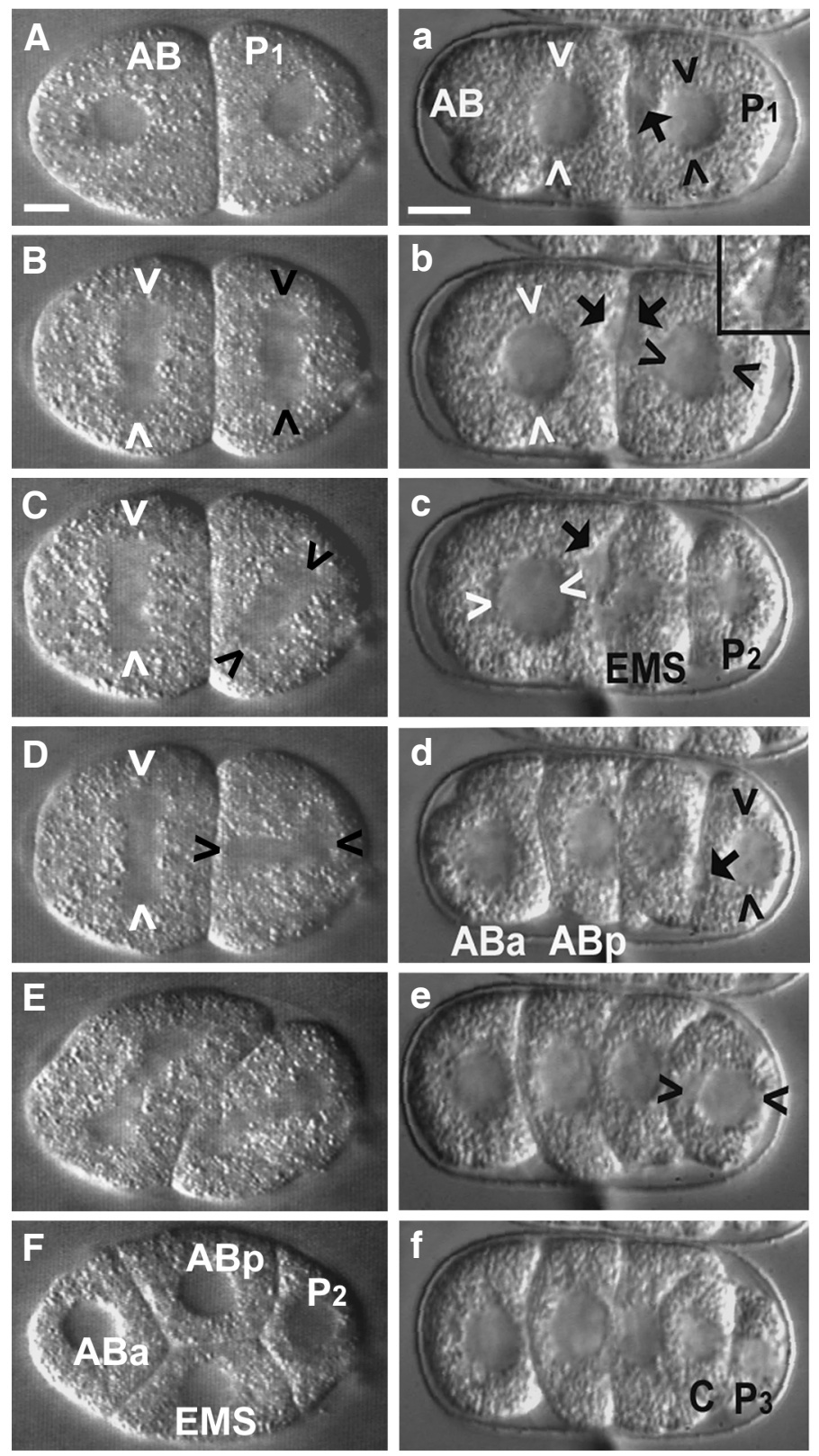

Fig. 4. Early cleavage patterns of Rhabditis sp (A-F) and $D$. coronatus (a-f). (A) 2-cell embryo, both blastomeres in interphase. (B) Simultaneous cleavage of $A B$ and $P_{1}$ with transverse orientation of cleavage spindles in both blastomeres. (C, D) Rotation of the nucleus/ centrosome complex in $P_{1}$. (E, F) Subsequent skewing of cells caused by mitotic forces and constraints of the eggshell leads to a rhombic arrangement. Arrowheads indicate orientation of cleavage spindles. (a) 2-cell embryo, start of mitosis and clear cortical region (CCR) in $P_{1}$ (arrow). (b) Centrosomal rotation essentially completed in $P_{1}$. CCR in both blastomeres (arrows); inset, magnification of CCR. (c) Centrosomal rotation essentially completed in $A B$ with prominent CCR (arrow). (d) Linear 4-cell stage, CCR in $P_{2}$ (arrow). (e) Centrosomal rotation essentially completed in $P_{2}$. (f) Linear arrangement of five blastomeres. Arrowheads, orientation of centrosomes/spindles. Orientation of embryo: anterior, left; dorsal, top. Scale bar, $10 \mu \mathrm{m}$. 
AB prior to centrosome rotation (Fig. 4b). We identified straight running cell borders in this area indicating that these structures are intracellular and not indentations of plasma membranes (Fig. 4b, inset). Initially, these CCRs persist after the division of $P_{1}$ (Fig. 4c), but then they disappear (Fig. $4 \mathrm{~d}$-f). The same process takes place in $\mathrm{P}_{2}$ (Fig. $4 \mathrm{~d}$-f) but not in the AB cells (Fig. 6 b', c'), i.e., formation of a CCR, rotation of the nuclear/centrosome complex and subsequent division with a-p spindle orientation.

As in $C$. elegans an induction by $P_{1}$ is required to ascertain a longitudinal spindle orientation in $A B$ and an a-p polarity in $A B$ descendants (Laufer et al., 1980; Bischoff and Schnabel, 2006), it

\section{C. elegans}
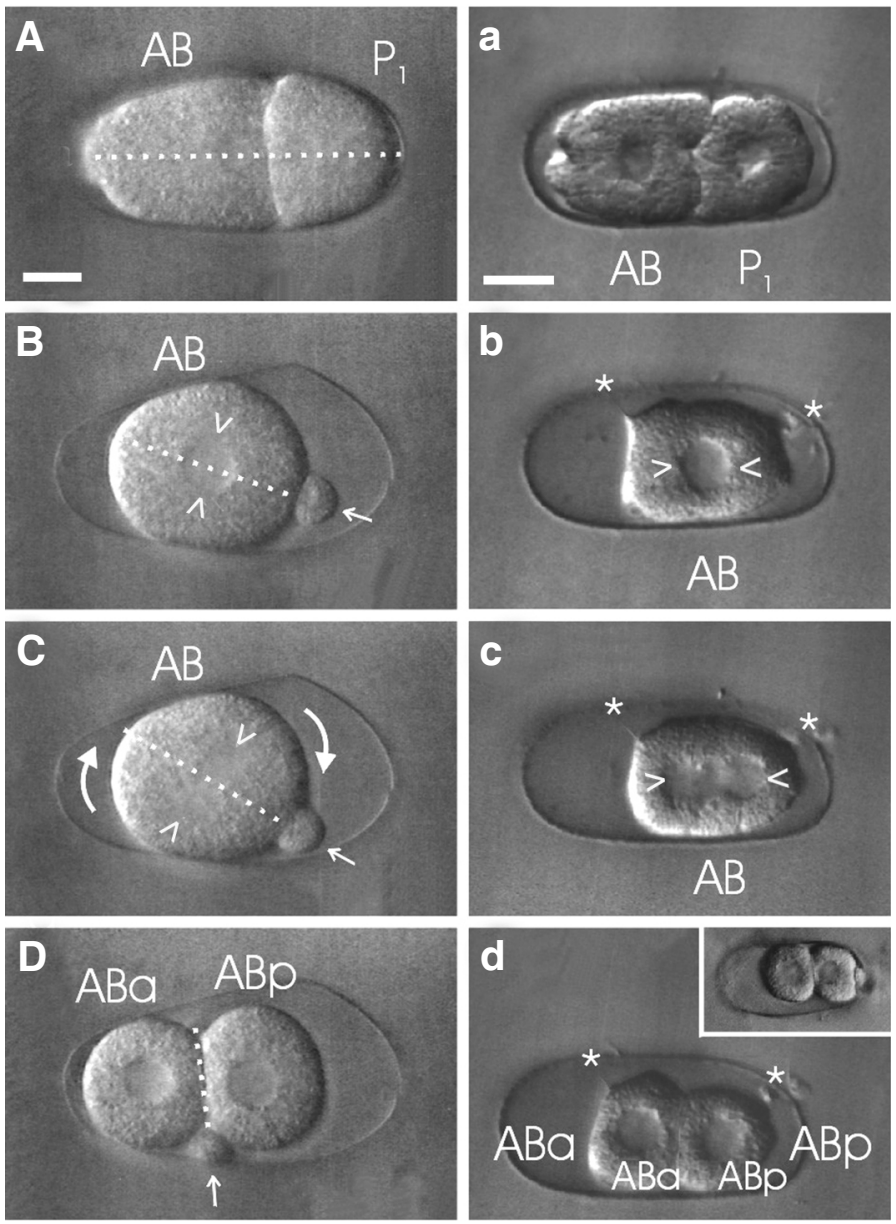

Fig. 5. Cell-autonomous spindle orientation in AB. (A-D) C. elegans. (a-d) D. coronatus. After removal of $P_{1}$ from an early 2-cell stage (A,B), the mitotic spindle in $A B$ forms in a transverse position. Due to a rotation of the complete blastomere (C), both daughter cells occupy an anteriorposterior (a-p) position in the eggshell (D). The position of the small $P_{1}$ fragment marks the posterior pole of $A B$. In D. coronatus, the isolated $A B$ cell (b) undergoes a division with a strict a-p position of the cleavage spindle (c) and consequently daughter cells occupy a-p positions in the eggshell (d). The same result was obtained when a $P_{1}$ fragment remained as a marker for the posterior pole of $A B$ (d) (see inset). Arrowheads, orientation of centrosomes/cleavage spindle; small arrow, remnant of $P_{1}$; large arrows, rotation of complete cell; dashed line, orientation of a-p axis; asterisks, cytoplasmic filament and a tiny remainder of $P_{1}$ respectively, as markers for anterior and posterior regions of $A B$. Orientation of embryo: anterior, left. Scale bar, $10 \mu \mathrm{m}$. seemed plausible that in $D$. coronatus the spindle rotation in $A B$ may be induced by the germline cell. To investigate this, we ablated $P_{1}$ in $D$. coronatus $(n=27)$ and found that nevertheless the $A B$ cleavage spindle occupied an a-p position. To exclude that this was due to a residual influence of the ablated cell, in a second series of experiments we physically removed $P_{1}$ through a laser-induced hole in the eggshell immediately after its birth (Fig. 5b). Isolated AB cells in $D$. coronatus $(n=8)$ performed divisions with a-p spindle orientations independent of whether $P_{1}$ had been removed completely (Fig. $5 \mathrm{~d}$ ) or a small cytoplasmic fragment had remained attached to $A B$ as a marker for the posterior pole (Fig. $5 d$, inset). Isolated $A B$ cells of $C$. elegans $(n=7)$ executed cleavages with a transverse spindle orientation like in intact embryos (Fig. 5 B,C). However, because during division the $A B$ cell rotated completely inside the eggshell, due to spatial restrictions of the eggshell, its daughters ultimately occupied anterior and posterior positions (Fig. 5 C,D). From these data we conclude that the longitudinal spindle orientation in the $\mathrm{AB}$ cell of $D$. coronatus as well as the transverse orientation in $C$. elegans are cell-autonomous processes that do not require an induction by $P_{1}$.

\section{EMS activity leads to disruption of linear cell arrangement and establishment of the dorsal-ventral axis}

To determine to what extent the linear 4-cell stage in $D$. coronatus subsequently results in an embryogenesis that differs from $C$. elegans, we analyzed further development, in particular with respect to axis formation, lineage-specific patterns and initiation of gastrulation.

In the 5-cell stage a dramatic rearrangement of cells takes place in D. coronatus, whereby $\mathrm{ABp}$ and EMS leave their positions in the linear sequence, thus establishing the dorsal-ventral axis, i.e., $A B p$ represents the dorsal and EMS the ventral side of the developing embryo (Fig. 6 A-D). Despite differences in the order of cleavages (Fig. 3), from this time onward the cellular pattern resembles that of the C. elegans wildtype and other related nematodes (Skiba and Schierenberg, 1992; Malakhov, 1994; Houthoofd et al., 2003). In contrast to $C$. elegans all nuclei contain prominent nucleoli, indicating synthetic activity (Fig. 6 A-D).

To investigate which of the blastomeres are actively involved in the early rearrangements in $D$. coronatus, we ablated individual blastomeres. After ablation of $\mathrm{ABp}$ (Fig. $6 \mathrm{a} ; \mathrm{n}=3)$, this cell was soon translocated from its original position (Fig. 6 b,c) and usually ended up ectopically at the posterior pole of the embryo (Fig. 6d). In such experimental embryos the proper movement of EMS to the ventral side and its asymmetric nuclear positioning were not affected (Fig. $6 c)$. In contrast, ablated EMS cells were found to remain in their original position for a long time and the typical early cell rearrangements did not occur (Fig. 6 a'-d'; n=3). From these results we conclude that an active movement of the EMS cell is required to allow correct pattern formation in the early $D$. coronatus embryo. We also ablated $P_{2}(n=3)$ to test its effect on the migration behavior of EMS and $\mathrm{ABp}$. We found that cellular rearrangements took place in the normal way (Fig. $6 \mathrm{a}^{*}-\mathrm{d}^{\star}$ ) giving no indication for a germline influence on this process.

\section{Absence of cleavage polarity reversal is associated with transiently variable patterns of posterior cells}

In $C$. elegans a reversal of cleavage polarity takes place in the germline cell $\mathrm{P}_{2}$ (see Introduction) leading to an invariant arrange- 

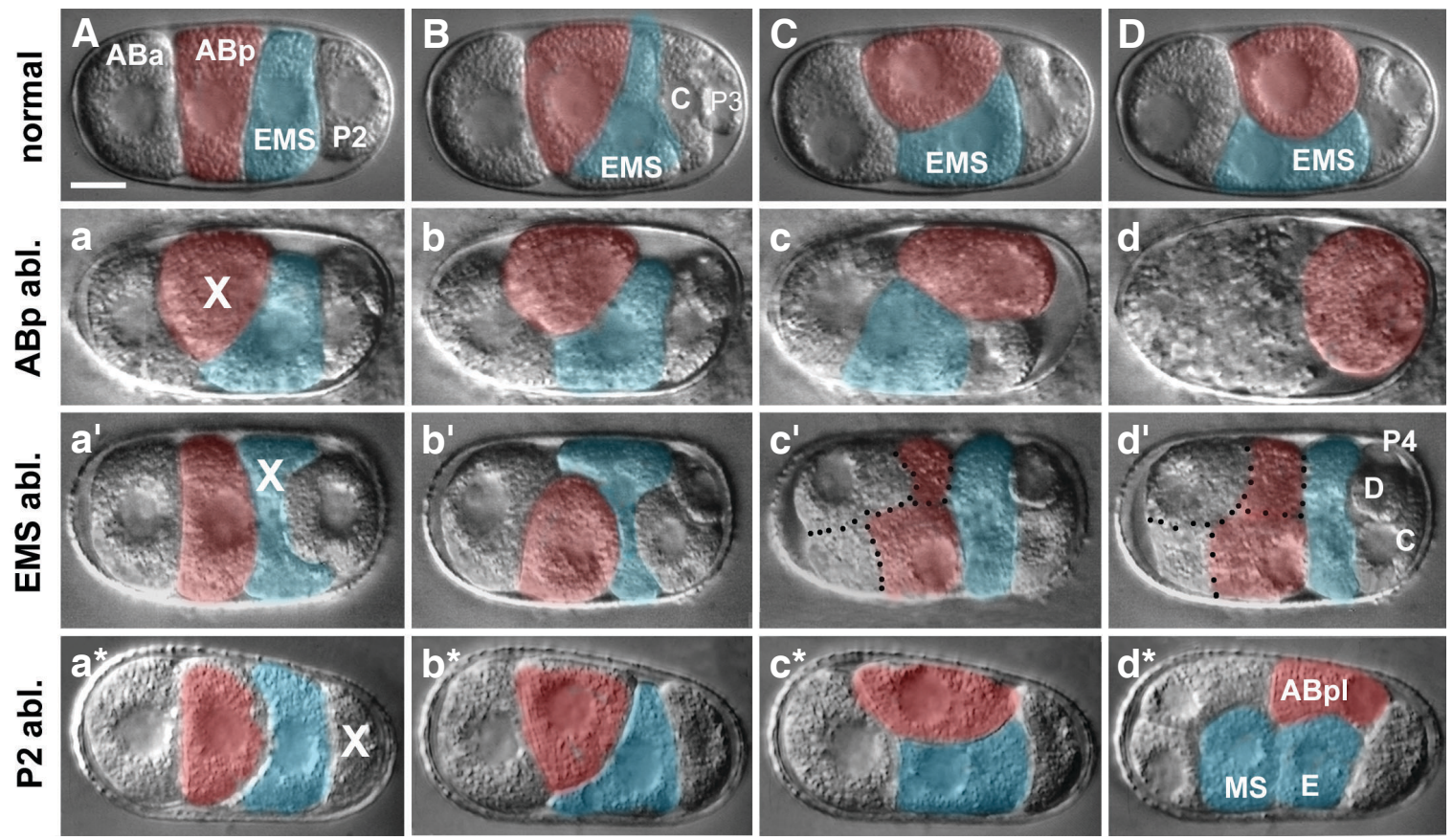

Fig. 6. Rearrangement of $\boldsymbol{D}$. coronatus blastomeres. (A-D) Untouched embryos. (a-d) After ablation of ABp. (a'-d') After ablation of EMS. (a*$\mathbf{d}^{*}$ ) After ablation of $P_{2}$. (A) Four blastomeres in one linear sequence. (B) 5-cell stage; $P_{2}$ has divided into $C$ and $P_{3}$; the $E M S$ has changed shape. (C) EMS has made contact to ABa. (D) EMS occupies a ventral and ABp a dorsal position in the embryo. (a) 5-cell embryo after ablation of ABp (red; crossed). (b,c) 5-cell stage; translocation of ABp and EMS (blue). (d) Terminal phenotype; posterior position of ABp. (a') 4-cell embryo after ablation of EMS (blue, crossed). (b') 5-cell stage; central position of EMS. (c') 7-cell stage; two AB nuclei out of focus. (d') 8-cell stage; dotted lines mark contours of the four $A B$ descendants. $\left(\mathbf{a}^{*}\right)$ 4-cell stage after ablation $P_{2}$. $\left(\mathbf{b}^{*}, \mathbf{c}^{*}\right)$ Rearrangements of EMS and ABp. (d*) 7-cell stage. For better visibility of $A B p$ and EMS images were colored. Orientation of embryo: anterior, left. Scale bar, $10 \mu \mathrm{m}$.

ment of early blastomeres. This polarity reversal was found to be absent in $A$. nanus (clade 11) but this is compensated by early cell migrations (Skiba and Schierenberg, 1992). In D. coronatus we made a similar observation. Comparing a larger number of individual embryos $(n=22)$ we found major variations in the positions of C, D, $\mathrm{P}_{3}$ and $\mathrm{P}_{4}$ (Fig. 7). In approximately half of the analyzed 5cell stages $P_{3}$ had no contact to $A B p(F i g .7 B, C)$. Essentially equal numbers could also be attributed to the four versions of 8-cell stages (Fig. 7 B1-C2; although cell positions were somewhat variable between embryos, with respect to cell contacts of $P_{4}$ each embryo could be assigned to one specific pattern). Dependent on their positions relative to each other, cells migrate and eventually merge into a single common pattern prior to the onset of gastrulation (Fig. 7D). The behavior of $\mathrm{P}_{4}$ appears to involve several phases. Initially, it loses its firm attachment to its sister D, shifts around, and only after the division of EMS shows a quite directed movement toward the E cell independent of whether it is close or further away from it. This suggests that at least the germline cell is able to sense its actual position and responds to signals from other cells in order to find its final position.

Despite the delayed division of the gut founder cell $E$ relative to $C$. elegans (Fig. 3), gastrulation in D. coronatus starts after the 24-cell stage, with the immigration of the two $E$ cell daughters essentially as found in $C$. elegans. However, before that, $\mathrm{P}_{4}$ divides again around the 23-cell stage (Fig. 3 ) while in $C$. elegans this division happens only later around the 100-cell stage (Deppe et al., 1978). Nevertheless, in both species $P_{4}$ generates descendants of similar size. The $\mathrm{P}_{4}$ daughters in $D$. coronatus behave like those in $C$. elegans (where they give rise to germ cells only; Sulston et al., 1983) in that both do not divide as far as we followed them (well beyond the 200-cell stage). In addition, they contain hardly any yolk granules and thus are much more transparent than somatic cells (not shown). Attempts to visualize germline with antibodies against $C$. elegans $\mathrm{P}$ granules failed.

Besides this case of premature germline division, we observed additional examples which can be interpreted as heterochronic shifts. These include the presence of 32 gut cell nuclei at hatching in $D$. coronatus, while $C$. elegans has only 20 at that time but adds another 10-14 nuclei during postembryonic development (Sulston and Horvitz, 1977). Preliminary observations indicate that the additional nuclei in $D$. coronatus reflect actual cell divisions rather than dinucleic cells.

\section{AB daughters execute different developmental programs}

In $C$. elegans the two daughters of the $A B$ cell are originally of equivalent developmental potential and only become different from each other after an inductive signal from $P_{2}$ has been received by $A B p$ (see introduction).

In $D$. coronatus $P_{2}$ never touches $A B p$ (Fig. 7A), and $P_{3}$ contacts $A B$ daughters only in about half of the analyzed embryos (Fig. 7 B,C) without any effect on normal development. Thus, in contrast to $C$. elegans, in $D$. coronatus this crucial interaction seems either be dispensable or to work without visible cell-cell contact. We therefore addressed the question whether here the developmental programs of $\mathrm{ABa}$ and $\mathrm{ABp}$ remain similar to each other or nevertheless become different. To do this we (1) studied 


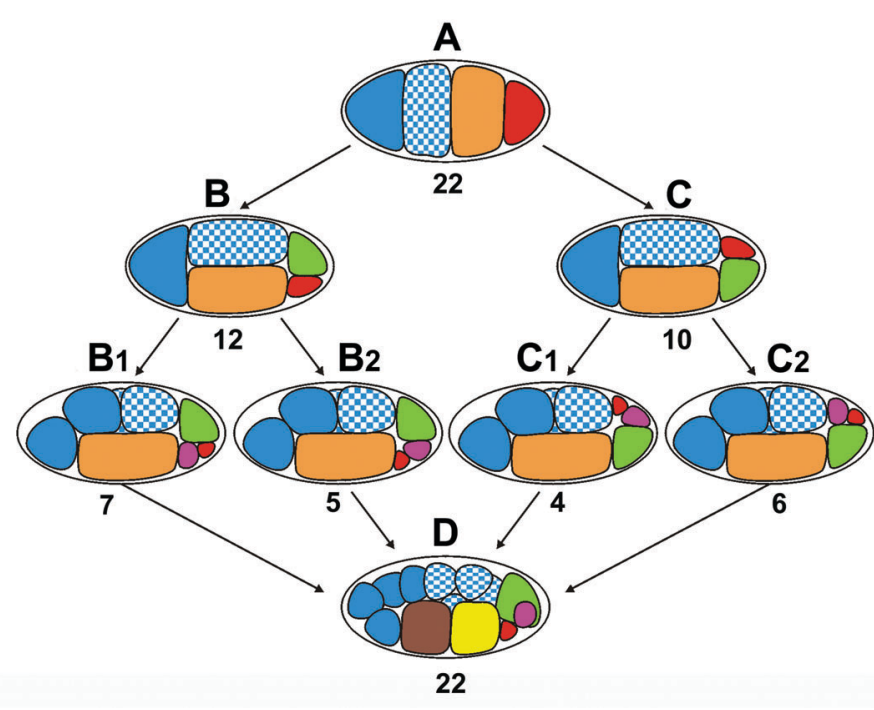

Fig. 7 (Left). Variable arrangement of blastomeres in 5- and 8-cell embryos of $\boldsymbol{D}$. coronatus. After division of the 4-cell stage (A), two 5cell variants $(\mathbf{B}, \mathbf{C})$ can form where $P_{3}$ touches either $E M S(\mathbf{B})$ or $A B p(\mathbf{C})$. With the division of $P_{3}$ four different variants (B1-C2) are generated, which eventually merge into a single pattern (D). Cell stage when $P_{4}$ touches $E$ may vary. Observed numbers of variants are given below embryos. Color code: $A B a$ (and descendants), solid blue; $A B p$ (and descendants), cross-hatched blue; $E M S$, orange; $C$, green; $D$, purple; germline $\left(P_{2}-P_{4}\right)$, red; MS, brown; E, yellow. Orientation of embryo: anterior, left; dorsal, top.

Fig. 8 (Right). Essentially identical arrangement of 128 AB cells in C. elegans (A-C) and D. coronatus (a-c). (A,a) Anterior view; dorsal, top. (B,b) Dorsal view; anterior, left. (C,c) Ventral view; anterior, left. For color code of 8 AB clones and MS descendants, see Fig. 3.

spatial pattern formation in the clones derived from these two cells and (2) compared the fates of selected blastomeres.

At a stage when $128 \mathrm{AB}$ cells are present (172 cells in total) the spatial arrangements are essentially indistinguishable between both species (Fig. 8) including the prominent splitting up of ABar into two separate clones in $C$. elegans and D. coronatus (Fig. 8A, a; light blue and bright red spheres). Descendants of $A B a$ and $A B p$ form reproducible spatial patterns that differ considerably from each other $(n=3)$. Our observations indicate that, like in $C$. elegans, $\mathrm{AB}$ cells in $D$. coronatus also contribute to hypodermis, neurons and pharynx (data not shown).

Moreover, we analyzed the fate of four selected ABa descendants (ABalapapaa, ABalappaaa, ABalppaapa and Abarpaaapp) which in $C$. elegans undergo early programmed cell death (i.e., in the $256 \mathrm{AB}$-cell stage), while the corresponding ABp descendants (i.e., ABplapapaa, etc.) execute different fates (Sulston et al., 1983). We found that in $D$. coronatus the situation is like in $C$. elegans, i.e., the four descendants of $A B a$ die $(n=3)$ but those derived from $A B p$ do not $(n=2)$. Our data demonstrate that also in $D$. coronatus descendants of $\mathrm{ABa}$ and $\mathrm{ABp}$ execute different fates.

\section{Cell ablation experiments indicate non-regulative develop- ment}

In C. elegans blastomeres are fixed early to a specific, essentially invariant lineage program (see Introduction), and eliminated cells are not replaced by others. In contrast, in $A$. nanus early blastomeres compete for a primary fate and the loss of one cell may cause a switch in the developmental program of another. For example, if EMS is ablated, its neighbor $\mathrm{C}$ takes over the EMS
A

C. elegans

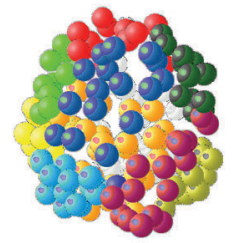

B

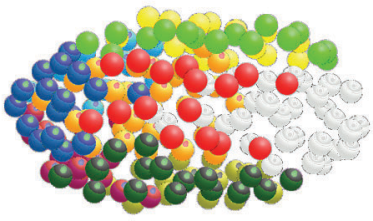

C

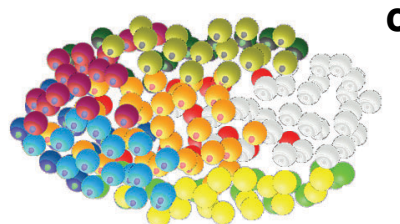

a

\section{D. coronatus}

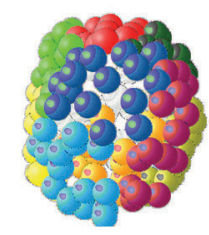

b

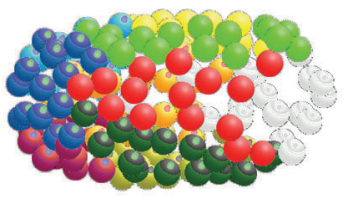

C

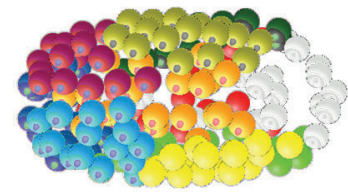

miegner and Schierenberg, 1999). develops slowly, is parthenogenetic and does not show a reversal of cleavage polarity, thus behaving like $A$. nanus in this regard (see above), we asked whether this species may show such regulative behavior as well. For this we ablated EMS as soon as it was born and analyzed the development of the $C$ cell $(n=8)$. In no case did we find indications for a lineage transformation, i.e., no separation into two founder cells with different cleavage rhythms took place, none of the early $\mathrm{C}$ descendants immigrated, and no differentiated gut cells were detected with the tissuespecific antibody ICB4 and by looking at birefringent gut granules.

Hence, with respect to early embryonic plasticity $D$. coronatus appears to be similar to $C$. elegans, indicating that regulative potential does not depend on developmental tempo or the mode of reproduction but may rather be correlated with phylogenetic position.

\section{Discussion}

In $D$. coronatus (clade 9; Fig. 1) a linear 4-cell embryo is formed. As such an arrangement has also been described for a variety of other nematodes in the classical literature (for references, see Malakhov, 1994), it can be asked whether it represents a more original pattern or is a derived character. Using outgroup comparisons, Dolinski et al. (2001) concluded that within Rhabditida (clades 7-12) the rhombic 4-cell pattern as found in $C$. elegans is ancestral to the tandem pattern, which thus must have evolved more than once independently in individual nematode branches. The latter view is supported by our observations of linearly ordered blastomeres in the phylogenetically very 
distant Ironus (clade 1; E.S., unpublished data), while other representatives of this taxon do not show such a pattern (Malakhov, 1994).

The process of nuclear/centrosome rotation was studied in detail by Hyman and White (1987) and Hyman (1989). It requires the activity of spindle microtubules that compete for attachment to a defined site at the anterior cortex of $P_{1}$. In $D$. coronatus the same process seems to takes place in both blastomeres of the 2-cell stage. This assumption is supported by our observation that in Diploscapter a prominent clear cortical region (CCR) appears in the cortex of both 2-cell stage blastomeres (Fig. 4b). It seems that this variant cell behavior between both species can best be attributed to an altered distribution of maternal factors responsible for capturing spindle microtubules.

A cortical structure resembling the CCR in D. coronatus was found in early ascidian embryos (Hibino et al., 1998). Orientation of mitotic spindles and their asymmetric translocation resulting in unequal divisions are induced by this structure called CAB ("centrosome-attracting body"). It contains a complex of specific polarity proteins including PAR- 6 and PAR-3 and appears to capture plus ends of spindle microtubules (Patalano et al., 2006). The way in which cellular asymmetries are generated there shows obvious similarities to $C$. elegans but also to other systems (Nishikata et al., 1999). A comparable effect on spindle behavior appears to be exerted by the RFM («region of the first midbody») in early embryos of the basal nematode $R$. culicivorax (clade 2; Schulze and Schierenberg, 2008).

What underlying mechanisms may have led during evolution from a transverse to a longitudinal spindle orientation in $A B$ or vice versa? One option is an altered expression of par genes (Nance, 2005). A single mutation in the gene par-3 of $C$. elegans leads to a linear D. coronatus-like 4-cell pattern (Kemphues et al., 1988). However, this mutant has an embryonic lethal phenotype and therefore the differences in the genetic program between both species must be more complex. In the par-2/par-3 double mutant where proteins are affected which are normally located at opposite poles of the zygote, the first mitotic spindle is longitudinally oriented (Cheng et al., 1995), indicating that neither gene is required for spindle rotation in $\mathrm{AB}$. It may be interesting to explore whether an RFM-like mechanism as found in $R$. culicivorax (Schulze and Schierenberg, 2008), which prevents a cell from following the centriolic principle (see above) may be present in $C$. elegans as well but then be normally overruled by par gene activity.

We found that in $D$. coronatus both $A B$ daughters become different from each other despite the lack of contact between $A B p$ and $\mathrm{P}_{2}$, which in $C$. elegans is required for proper cell signaling (Priess and Thomson, 1987; Priess 2005). One alternative is that fate specification in $A B$ cells is fundamentally different between the two species, despite their close phylogenetic relationship. In such a scenario the a-p polarity (which in C. elegans but not in $D$. coronatus and other parthenogenetic species is initiated by the entrance of the sperm; Goldstein and Hird, 1996; Lahl et al., 2003; Cowan and Hyman; 2004), leads to a graded distribution of cytoplasmic factors in AB. Spindle rotation takes place not only in the germline resulting in differential segregation of maternal gene products (Strome and Wood, 1983; Strome and Lehmann, 2007) but also between $\mathrm{ABa}$ and $\mathrm{ABp}$, making an induction dispensable. Alternatively, germline signals may be transmitted over distance.
In a series of elegant recombination experiments Bischoff and Schnabel (2006) showed that in fact $P_{2}$ in $C$. elegans can polarize cells that it does not touch. Their data support a transmission mechanism whereby the germline signal is relayed, i.e., renewed in each cell it travels through before reaching its final target.

We have initiated experiments to discern between these two options. So far, our approach is hampered by a high sensitivity of $D$. coronatus blastomeres to experimental interference and limited transparency of embryos to determine terminal cell fates.

The variable relative positions of $\mathrm{C}, \mathrm{D}$ and $\mathrm{P}_{4}$ in $D$. coronatus require more or less extensive migrations to reach the standard pattern prior to the onset of gastrulation (Fig. 7). This is different to $C$. elegans where during the early cleavage phase these cells are «automatically» placed at their correct position. The most plausible explanation for the directed migration of $\mathrm{P}_{4}$ to the gut founder cell $E$ is that the latter sends a signal which the germline cell can sense. Cell isolation and recombination experiments in $C$. elegans have demonstrated the existence of a cell surface recognition mechanism between gut precursor and germline cells (Goldstein, 1993). As in D. coronatus $\mathrm{P}_{4}$ is often placed quite far away from its terminal position adjacent to the gut founder (Fig. 7 $\mathrm{C} 1, \mathrm{C} 2)$, signaling must work over distance. Here a graded substance guiding the germline cell along one or more blastomeres to its final destination could be involved. This would constitute a so far undescribed way of cell-cell interaction in nematode embryos. It was shown that lysophospholipids play important roles in the migration of germ cells in vertebrates and invertebrates and a guiding function of a phospholipid gradient has been suggested (Renault and Lehmann, 2006). Recently Schnabel et al. (2006) proposed a model explaining migrations of $A B$ descendants in $C$. elegans. They suggest that blastomeres are neither guided by graded signals nor by discrete guide posts but are sorted by a mechanism coupled to cell identity.

Based on our limited light microscopical analysis, we cannot exclude that an initial contact between cells (i.e., EMS and $P_{2}$ ) is perpetuated, e.g., in the form of filopodia or tunneling nanotubes (Rustom et al., 2004), is remembered in some other way through consecutive cell divisions, until $\mathrm{E}_{\text {and }} \mathrm{P}_{4}$ are present, or the proper contact partner is found via a «trial and error» mechanism (Hardin and McClay, 1990). While in a study using EM serial sections from early C. elegans embryos (Krieg et al., 1978) no such connecting structures between non-adjacent cells were identified, it may be worthwhile to search more specifically for a visible structural basis of cell-cell communication between germline and gut precursors in $D$. coronatus and other species.

Our data indicate that the activity of the EMS cell initiates the rearrangements in the 5 -cell stage resulting in a $C$. elegans-like pattern (Fig. 6). The ability of EMS to change its shape and then to move may be explained with a shift in the timing of events. In C. elegans the two granddaughters of EMS elongate and then migrate into the center of the embryo during the initial phase of gastrulation (von Ehrenstein and Schierenberg, 1980; Junkersdorf and Schierenberg, 1992; Nance and Priess, 2002). In several members of the taxon Plectida (clade 6) gastrulation starts one cell generation earlier with the immigration of the single gut founder cell E (Lahl et al., 2003). In D. coronatus already EMS becomes competent to migrate or neighboring cells exhibit prematurely necessary cell surface molecules to allow it.

Heterochrony is often considered the single most important 
process of evolutionary change (for discussion, see Raff, 1996). While prominent examples concern postembryonic events (e.g., neoteny or larval vs. direct development), several early embryonic modifications we have found in $D$. coronatus can be interpreted as heterochronic shifts (e.g. premature generation and division of the primordial germ cell; Fig. 3). It remains to be determined whether the movement of the EMS cell can be interpreted along the same line. A more detailed comparative analysis of nematode embryogenesis on a cellular and molecular level should give us a better estimate as to which of the developmental differences between species cannot be explained with heterochronies and to what extent variances like the ones described here may have an adaptive value, i.e., affect fitness of the hatched larva.

\section{Materials \& Methods}

\section{Nematode culture and strains}

All strains were cultured on agar plates with the uracil-requiring strain of $E$. coli OP50 as a food source, essentially as described by Brenner (1974) except that, to reduce contamination with other bacteria, we used minimal medium plates (Lahl et al., 2003). Diploscapter coronatus was kindly provided by Paul De Ley, University of California, Riverside. Rhabditis sp. (strain designation ES104) was isolated from the local greenhouse and is reminiscent of Rhabditis dolichura.

\section{Microscopical analysis and 3-D reconstructions}

Development was studied with Nomarski optics using a 100x objective. For cell lineage studies early stage embryos were collected from agar plates with a drawn-out pasteur pipette as early as the the 1-cell stage. Specimens were placed on microscope slides carrying a thin agar layer as a mechanical buffer and covered with a coverslip sealed on the edges with petroleum jelly. Depending on the species, development was either recorded on video tape, as described in Lahl et al., 2003, or stored in digital form using a 4-D microscope with 15-25 optical sections/embryo and 15-60 sec time intervals between scans (Schnabel et al.,1997). Supported by specific software programs (Simi Biocell, München), cell behavior was traced and cell lineages were analyzed. 3-D reconstructions of nuclear positions were generated which can be freely rotated in all three dimensions. Antibodies K76 and L416 against germline specific cytoplasmic granules in C. eleganswere used as described in Strome and Wood (1983) and antibody ICB4 (Okamoto and Thomson, 1985), which visualizes differentiated gut cells in both species.

\section{Laser micromanipulation}

For cell ablation and extrusion experiments embryos were mounted on polylysine-coated slides in distilled water which was then replaced by an embryonic growth medium (Edgar, 1995) as described by Wiegner and Schierenberg (1998). Cells were ablated by repeated short pulses of an $\mathrm{N}_{2}$-pumped laser microbeam coupled to a microscope via glassfiber optics (Photonic Instruments, St. Charles, III.; laser dye, Coumarin; absorption maximum $440 \mathrm{~nm}$ ). For extrusions the eggshell was perforated with the laser and individual blastomeres were squeezed out by gentle pressure on the coverslip.

\section{Acknowledgments}

We thank Paul De Ley, University of California, Riverside, for the Diploscapter strain and for sharing his expertise in nematode identification, Walter Sudhaus, Freie Universität, Berlin, for other nematode strains with linear blastomere arrangements, Susan Strome for antibodies, Randy Cassada for critical reading of the manuscript, and the Deutsche Forschungsgemeinschaft (SFB 680) for support.

\section{References}

BISCHOFF, M. and SCHNABEL, R. (2006). A posterior centre establishes and maintains polarity of the Caenorhabditis elegans embryo by a Wnt-dependent relay mechanism. PLoS Biol 4: e396. DOI: 10.1371/journal.pbio.0040396

BLAXTER, M.L., DE LEY, P., GAREY, J.R., LIU, L.X., SCHELDEMAN, P., VIERSTRAETE, A., VANFLETEREN, J.R., MACKEY, L.Y., DORRIS, M., FRISSE, L.M. et al. (1998). A molecular evolutionary framework for the phylum Nematoda. Nature 392: 71-75.

BOVERI, T. (1899). Die Entwicklung von Ascaris megalocephala mit besonderer Rücksicht auf die Kernverhältnisse. In: Festschrift für C. v. Kupffer. Gustav Fischer Verlag, Jena, pp. 383-430.

BRENNER, S. (1974). The genetics of Caenorhabditis elegans. Genetics 77: 71-94.

CHENG, N.N., KIRBY, C.M. and KEMPHUES, K.J. (1995). Control of cleavage spindle orientation in Caenorhabditis elegans: the role of the genes par-2 and par-3. Genetics 139: 549-559.

COSTELLO, D.P. (1961). On the orientation of centrioles in dividing cells, and its significance: a new contribution to spindle mechanics. Biol. Bull. Mar. Biol. Lab. Woods Hole 120: 285-312.

COWAN, C.R. and HYMAN, A.A. (2004). Centrosomes direct cell polarity independently of microtubule assembly in C. elegans embryos. Nature 431: 92-96.

DE LEY, P. and BLAXTER, M.L. (2002). Systematic Position and Phylogeny. In: D.L.Lee (ed.) The Biology of Nematodes.Taylor and Francis, London, pp. 1-30.

DOLINSKI, C., BALDWIN, J.G. and THOMAS, W.K. (2001). Comparative survey of early embryogenesis of Secernentea (Nematoda), with phylogenetic implications. Can. J. Zool. 79: 82-94.

EDGAR, L.G. (1995). Blastomere culture and analysis. Methods Cell Biol. 48: 303321.

EISENMANN, D.M. (2005). Wnt signaling. WormBook, ed. The C. elegans Research Community, WormBook, doi/10.1895/wormbook.1.7.1, http:// www.wormbook.org

GOLDSTEIN, B. (1993). Establishment of gut fate in the $E$ lineage of $C$. elegans: the roles of lineage-dependent mechanisms and cell interactions. Development 118: 1267-1277.

GOLDSTEIN, B., FRISSE, L.M. and THOMAS, W.K. (1998). Embryonic axis specification in nematodes: evolution of the first step in development. Curr. Biol. 8: $157-160$.

GOLDSTEIN, B. and HIRD, S.N. (1996). Specification of the anteroposterior axis in Caenorhabditis elegans. Development 122: 1467-74.

GREENWALD, I. (2005). LIN-12/Notch signaling in C. elegans. WormBook, ed. The C. elegans Research Community, WormBook, doi/10.1895/wormbook.1.10.1 http://www.wormbook.org

HARDIN, J. and MCCLAY, D.R. (1990). Target recognition by the archenteron during sea urchin gastrulation. Dev. Biol. 142: 86-102.

HIBINO, T., NISHIKATA, T. and NISHIDA, H. (1998). Centrosome-attracting body: a novel structure closely related to unequal cleavages in the ascidian embryo. Dev. Growth Differ. 40: 85-95.

HOLTERMAN, M., VAN DER WURFF, A., VAN DEN ELSEN, S., VAN MEGEN, H., BONGERS, T., HOLOVACHOV, O., BAKKER, J. and HELDER, J. (2006). Phylum-wide analysis of SSU rDNA reveals deep phylogenetic relationships among nematodes and accelerated evolution toward crown clades. Mol. Biol. Evol. 23: 1792-1800.

HOUTHOOFD, W., JACOBSEN, K., MERTENS, C., VANGESTEL, S., COOMANS, A. and BORGONIE, G. (2003). Embryonic cell lineage of the marine nematode Pellioditis marina. Dev. Biol. 258: 57-69.

HOUTHOOFD, W., WILLEMS, M., VANGESTEL, S., MERTENS, C., BERT, W. and BORGONIE, G. (2006). Different roads to form the same gut in nematodes. Evol. Dev. 8: 362-369.

HYMAN, A.A. (1989). Centrosome movement in the early divisions of Caenorhabditis elegans: a cortical site determining centrosome position. J. Cell. Biol. 109: 1185-1193.

HYMAN, A.A. and WHITE, J.G. (1987). Determination of cell division axes in the early embryogenesis of Caenorhabditis elegans. J. Cell. Biol. 105: 2123-2135.

JUNKERSDORF, B. and SCHIERENBERG, E. (1992). Embryogenesis in C. 
elegans after elimination of individual blastomeres or induced alteration of the cell-devision order. Roux's Arch. Dev. Biol. 202: 17-22.

KEMPHUES, K.J., PRIESS, J.R., MORTON, D.G. and CHENG, N.S. (1988). Identification of genes required for cytoplasmic localization in early $C$. elegans embryos. Cell 52: 311-320.

KIONTKE, K., BARRIERE, A., KOLOTUEV, I., PODBILEWICZ, B., SOMMER, R., FITCH, D.H. and FELIX, M.A. (2007). Trends, stasis, and drift in the evolution of nematode vulva development. Curr. Biol. 17: 1925-1937.

KRIEG, C., COLE, T., DEPPE, U., SCHIERENBERG, E., SCHMITT, D., YODER, B. and CON EHRENSTEIN, G. (1978). The cellular anatomy of embryos of the nematode Caenorhabditis elegans. Analysis and reconstruction of serial section electron micrographs. Dev. Biol. 65: 193-215.

LAHL, V., HALAMA, C. and SCHIERENBERG, E. (2003). Comparative and experimental embryogenesis of Plectidae (Nematoda). Dev. Genes Evol. 213: 18-27.

LAHL, V., SADLER, B. and SCHIERENBERG, E. (2006). Egg development in parthenogenetic nematodes: variations in meiosis and axis formation. Int. J. Dev. Biol. 50: 393-398.

LAUFER, J.S., BAZZICALUPO, P. and WOOD, W.B. (1980). Segregation of developmental potential in early embryos of Caenorhabditis elegans. Cell 19: 569-577.

LAUGSCH, M. and SCHIERENBERG, E. (2004). Differences in maternal supply and early development of closely related nematode species. Int. J. Dev. Biol. 48: 655-662.

MALAKHOV, V.V. (1994). Nematodes. Structure, Development, Classification and Phylogeny Smithsonian Institution Press, Washinghton.

MELLO, C.C., DRAPER, B.W. and PRIESS, J.R. (1994). The maternal genes apx1 and glp- 1 and establishment of dorsal-ventral polarity in the early $C$. elegans embryo. Cell 77: 95-106.

NANCE, J. (2005). PAR proteins and the establishment of cell polarity during $C$. elegans development. Bioessays 27: 126-135.

NANCE, J. and PRIESS, J.R. (2002). Cell polarity and gastrulation in C. elegans. Development 129: 387-397.

NISHIKATA, T., HIBINO, T. and NISHIDA, H. (1999). The centrosome-attracting body, microtubule system, and posterior egg cytoplasm are involved in positioning of cleavage planes in the ascidian embryo. Dev. Biol. 209: 72-85.

OKAMOTO, H. and THOMSON, J.N. (1985). Monoclonal antibodies which distinguish certain classes of neuronal and supporting cells in the nervous tissue of the nematode Caenorhabditis elegans. J Neurosci 5: 643-653.

PATALANO, S., PRULIERE, G., PRODON, F., PAIX, A., DRU, P., SARDET, C. and CHENEVERT, J. (2006). The aPKC-PAR-6-PAR-3 cell polarity complex localizes to the centrosome attracting body, a macroscopic cortical structure responsible for asymmetric divisions in the early ascidian embryo. J. Cell. Sci. 119: 1592-1603.

PRIESS, J.R. (2005). Notch signaling in the C. elegans embryo. WormBook, ed. The C. elegans Research Community, WormBook, doi/10.1895/wormbook.1.4.1, http://www.wormbook.org.

PRIESS, J.R. and THOMSON, J.N. (1987). Cellular interactions in early C. elegans embryos. Cell 48: 241-250.

RAFF, R.A. (1996). The Shape of Life: Genes, Development and the Evolution of the Animal Form. University of Chicago Press.

RENAULT, A.D. and LEHMANN, R. (2006). Follow the fatty brick road: lipid signaling in cell migration. Curr. Opin. Genet. Dev. 16: 348-354.
ROCHELEAU, C.E., DOWNS, W.D., LIN, R., WITTMANN, C., BEI, Y., CHA, Y.H., ALI, M., PRIESS, J.R. and MELLO, C.C. (1997). Wnt signaling and an APCrelated gene specify endoderm in early $C$. elegans embryos. Cell 90: 707-716.

RUSTOM, A., SAFFRICH, R., MARKOVIC, I., WALTHER, P. and GERDES, H.H. (2004). Nanotubular highways for intercellular organelle transport. Science 303: 1007-1010.

SCHIERENBERG, E. (1987). Reversal of cellular polarity and early cell-cell interaction in the embryos of Caenorhabditis elegans. Dev. Biol. 122: 452-463.

SCHIERENBERG, E. (2001). Three sons of fortune: early embryogenesis, evolution and ecology of nematodes. Bioessays 23: 841-847.

SCHIERENBERG, E. (2005). Unusual cleavage and gastrulation in a freshwater nematode: developmental and phylogenetic implications. Dev. Genes Evol. 215: 103-108.

SCHNABEL, R., BISCHOFF, M., HINTZE, A., SCHULZ, A.K., HEJNOL, A., MEINHARDT, H. and HUTTER, H. (2006). Global cell sorting in the $C$. elegans embryo defines a new mechanism for pattern formation. Dev. Biol. 294: 418431.

SCHNABEL, R., HUTTER, H., MOERMAN, D. and SCHNABEL, H. (1997). Assessing normal embryogenesis in Caenorhabditis elegans using a 4D microscope: variability of development and regional specification. Dev. Biol. 184: 234-265.

SCHULZE, J. and SCHIERENBERG, E. (2008). Cellular pattern formation, establishment of polarity and segregation of colored cytoplasm in embryos of the nematode Romanomermis culicivorax. Dev. Biol. 315: 426-436.

SKIBA, F. and SCHIERENBERG, E. (1992). Cell lineages, developmental timing, and spatial pattern formation in embryos of free-living soil nematodes. Dev. Biol. 151: 597-610.

STROME, S. and LEHMANN, R. (2007). Germ versus soma decisions: lessons from flies and worms. Science 316: 392-393.

STROME, S. and WOOD, W.B. (1983). Generation of asymmetry and segregation of germ-line granules in early $C$. elegans embryos. Cell 35: 15-25.

SULSTON, J.E. and HORVITZ, H.R. (1977). Post-embryonic cell lineages of the nematode, Caenorhabditis elegans. Dev. Biol. 56: 110-156.

SULSTON, J.E., SCHIERENBERG, E., WHITE, J.G. and THOMSON, J.N. (1983). The embryonic cell lineage of the nematode Caenorhabditis elegans. Dev. Biol. 100: 64-119.

TAHSEEN, Q., JAIRAJPURI, M.S. and AHMAD, I. (1991). Observations on the embryonic and post-embryonic development of Diploscapter orientalis. Revue Nématol. 14: 251-260.

THORPE, C.J., SCHLESINGER, A., CARTER, J.C. and BOWERMAN, B. (1997). Wnt signaling polarizes an early $C$. elegans blastomere to distinguish endoderm from mesoderm. Cell 90: 695-705.

VON EHRENSTEIN, G. and SCHIERENBERG, E. (1980). Cell lineages and development of Caenorhabditis elegans and other nematodes. In: Nematodes as biological models. Zuckerman, B.M. (ed.), pp. 1-71. Academic Press, NY.

WIEGNER, O. and SCHIERENBERG, E. (1998). Specification of gut cell fate differs significantly between the nematodes Acrobeloides nanus and Caenorhabditis elegans. Dev. Biol. 204: 3-14.

WIEGNER, O. and SCHIERENBERG, E. (1999). Regulative development in a nematode embryo: a hierarchy of cell fate transformations. Dev. Biol. 215: 1-12.

WYLIE, C. (1999). Germ cells. Cell 96: 165-174.

ZUR STRASSEN, O. (1896). Embryonalentwicklung der Ascaris megalocephala. Arch. Entwicklungsmech. 3: 27-105. 


\section{Further Related Reading, published previously in the Int. J. Dev. Biol.}

See our Special Issue Evolution and Development, edited by Jaume Baguñà and Jordi García Fernández at:

http://www.ijdb.ehu.es/web/contents.php?vol=47\&issue=7-8

The embryonic cell lineage of the nematode Rhabditophanes sp.

Houthoofd W, Willems M, Jacobsen K, Coomans A, Borgonie G.

Int J Dev Biol. (2008) 52:963-7.

Cellular commitment and differentiation in the organ of Corti

Matthew W. Kelley

Int. J. Dev. Biol. (2007) 51: 571-583

Egg development in parthenogenetic nematodes: variations in meiosis and axis formation.

Lahl V, Sadler B, Schierenberg E.

Int J Dev Biol. (2006) 50: 393-8.

From embryonic induction to cell lineages: revisiting old problems for modern study.

Okada TS.

Int J Dev Biol. (2004) 48:739-42.

Differences in maternal supply and early development of closely related nematode species.

Laugsch M, Schierenberg E.

Int J Dev Biol. (2004) 48: 655-62.

2006 ISI **Impact Factor $=3.577^{* *}$

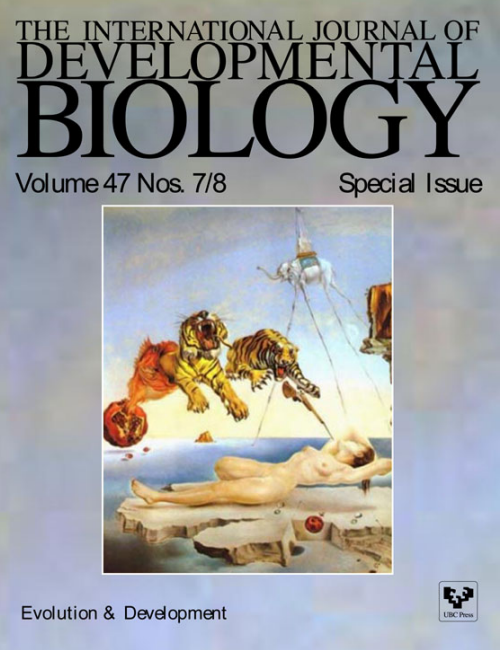

